\title{
Erratum to: Water Quality Characterization in the Northern Florida Everglades
}

\author{
James A. Entry
}

Published online: 5 June 2012

(C) Springer Science+Business Media B.V. 2012

\section{Erratum to: Water Air Soil Pollut DOI 10.1007/s11270-012-1105-9}

In the original publication of this article (10.1007/ s11270-012-1105-9), Figure 2a unfortunately contained an error. The label "mg CaL ${ }^{-1}$ " should have been "Meq $\mathrm{ALK} \mathrm{L}^{-1}$ ". The correct figure is reproduced on the next page.

The online version of the original article can be found at http:// dx.doi.org/10.1007/s11270-012-1105-9.

\section{J. A. Entry}

Everglades Program Team, Everglades National Park, US Department of Interior,

10218 Lee Road,

Boynton Beach, FL 33473-9741, USA

\author{
Present Address: \\ J. A. Entry $(\triangle)$ \\ Nurtigrown LCC, \\ 9250 Bendix Road, North, Suite 545, \\ Colombia, MD 21045, USA \\ e-mail: jim.entry@nutrigrown.com
}

Fig. 2 a, b Plots of alkalinity (ALK) and conductivity (SpC) values in Refuge water with distance from the canal (in kilometers) and percent of the canal values with distance $(d)$ from the canal (in kilometer) of the Loxahatachee National Wildlife Refuge, Boynton Beach, Florida. a $r^{2}=0.78$; ALK $=5.250-0.8546 \times d+0.1024 \times d^{2}-$ $0.0047 d^{3} ; n=947$ taken at 40 sampling locations. b. $r^{2}=0.70 ; \mathrm{SpC}=$ $6.649-0.9177 \times d+0.1439 \times d^{2}-0.0073 \times d^{3} ; n=947$ taken at 40 sampling locations. c, d Plots of the total dissolved solids (TDS) and hydrogen ion $(\mathrm{pH})$ concentrations in Refuge water with distance from the canal (in kilometers) and percent of the canal values with distance $(d)$ from the canal (in kilometers) of the Loxahatachee National Wildlife Refuge, Boynton Beach, Florida. c $r^{2}=0.61$; TDS $=6.1981-0.8314 \times d+0.1428 \times d^{2}-0.0076 \times d^{3} ; n=947$ taken at 40 sampling locations. d $r^{2}=0.49 ; \mathrm{pH}=7.407-0.5285 \times d+$ $0.09224 \times d^{2}-0.0052 \times d^{3} ; n=947$ taken at 40 sampling locations. e, f Plots of turbidity (TB) and (Ca) concentrations in Refuge water with distance from the canal (in kilometer) and percent of the canal values with distance $(d)$ from the canal (in kilometer) of the Loxahatachee National Wildlife Refuge, Boynton Beach, Florida. e $r^{2}=$ $0.46 ; \mathrm{TB}=1.5941-1.0324 \times d+0.0238 \times d^{2}-0.0148 \times d^{3} ; n=947$ taken at 40 sampling locations. $\mathbf{f} r^{2}=0.78 ; \mathrm{Ca}=4.2250-1.0178 \times$ $d+0.1594 \times d^{2}-0.0083 \times d^{3} ; n=947$ taken at 40 sampling locations. e, f Plots of chloride $(\mathrm{Cl})$ and sulfate $\left(\mathrm{SO}_{4}\right)$ concentrations in Refuge water with distance from the canal (in kilometer) and percent of the canal values with distance $(d)$ from the canal (in kilometer) of the Loxahatachee National Wildlife Refuge, Boynton Beach, Florida. g $r^{2}=0.57 ; \mathrm{Cl}=4.5937-0.8384 \times d+0.1437 \times d^{2}-$ $0.0076 \times d^{3} ; n=947$ taken at 40 sampling locations. h $r^{2}=0.64$; $\mathrm{SO}_{4}=3.5264-1.7329 \times d+0.2895 \times d^{2}-0.0154 \times d^{3} ; n=947$ taken at 40 sampling locations 

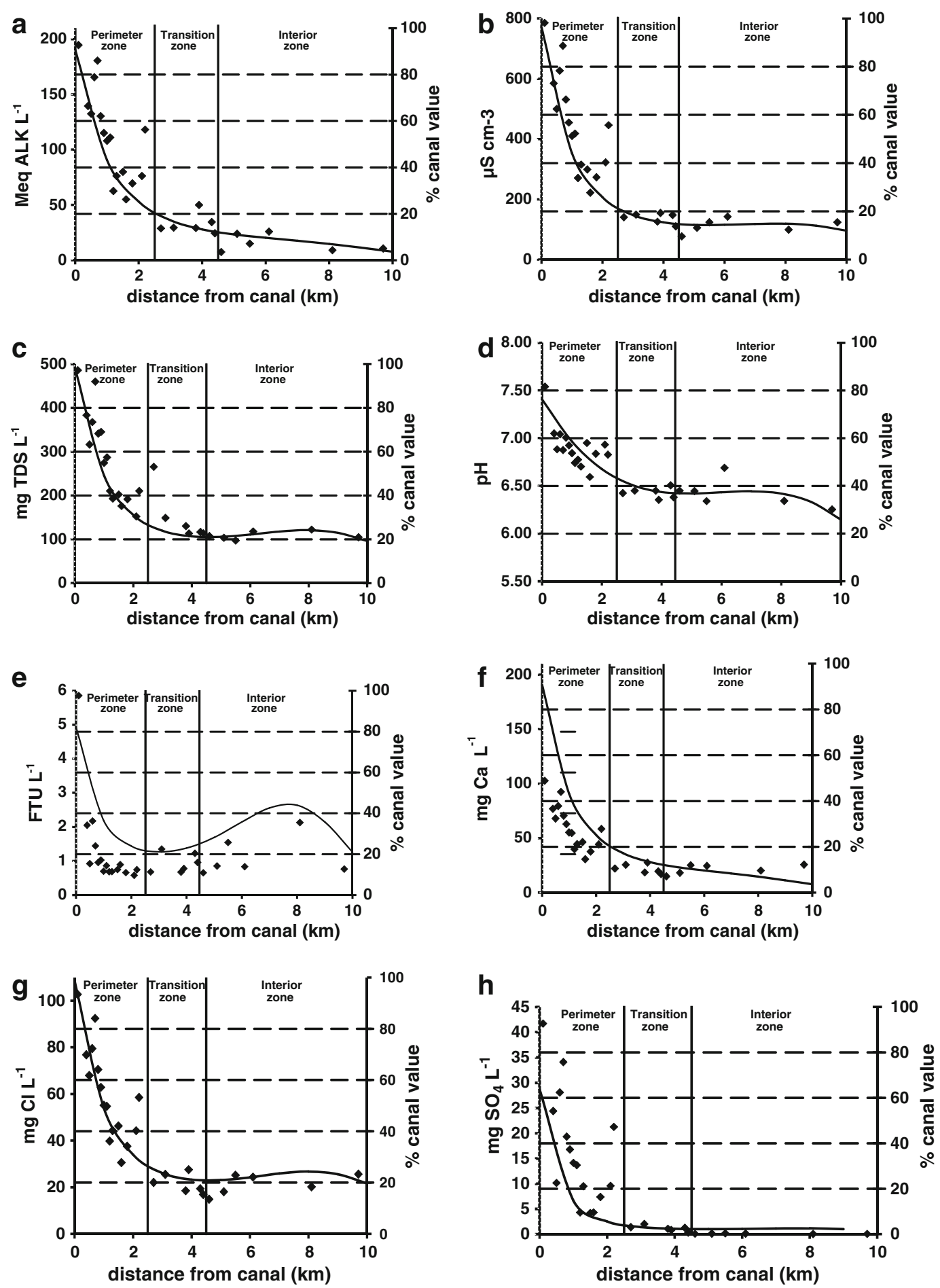